\title{
Fine Needle Diagnosis in Lumbar Osteomyelitis
}

\author{
Kedar B. Joshi, M.B., B.S., M.D., and Ray A. Brinker, M.D. \\ Department of Radiology, University of Michigan Medical School, \\ Wayne County General Hospital, Westland, Michigan, USA
}

\begin{abstract}
Lumbar vertebral body and disk infection, presenting as low back pain, is a relatively uncommon disease but is seen more often in drug addicts. Radiographs show typical changes of infection of the lumbar vertebrae and adjacent disc. Under local anesthesia a fine needle is placed, saline injected, and aspirated. The entire needle-syringe unit is submitted to the bacteriology department. Pseudomonas infection is usually found. This method of diagnosis is simple, cost effective, well accepted by the patients, and can be done on outpatients.
\end{abstract}

Key words: Osteomyelitis - Lumbar infection Needle aspiration diagnosis.

An accurate diagnosis is always necessary in a vertebral destructive lesion (Fig. 1). In a presumed bacterial infection the organism must be cultured and antibiotic sensitivity determined. Diagnostic aspiration biopsy [2] was first popularized in the 1930's. We have applied this general technique to the diagnosis of lumbar osteomyelitis. This can be done on an out-patient, is cost effective, and gives exact bacteriologic diagnosis for definitive medical regimen.

A portion of this material was presented (RAB) as a work-inprogress at the XIIth Symposium Neuroradiologicum, Washington, D.C., 1982

Clinical results of this work were presented (KBJ) at the 68 th Scientific Assembly and Annual meeting of the Radiologic Society of North America, Chicago, IL, November 28-December 3, 1982

Address reprint requests to: Ray A Brinker, M.D., WCGH XRay. 2345 Merriman Road, Westland, MI 48185, USA

\section{Materials and Methods}

We use a $15-20 \mathrm{~cm}$ (6-8 inch) thin (22 gauge) stainless steel needle with stylet. In addition, local anesthetic and saline are needed. Visualization is best done with a C-arm fluoroscope utilizing video storage and hard copy capabilities. The table should have a "cut-out" for easy changing from vertical to horizontal fluoroscopy (Figs. 2 and 3 ).

The patient is placed prone with the C-arm mobile fluoroscopy unit positioned for biplane visualization. The specially

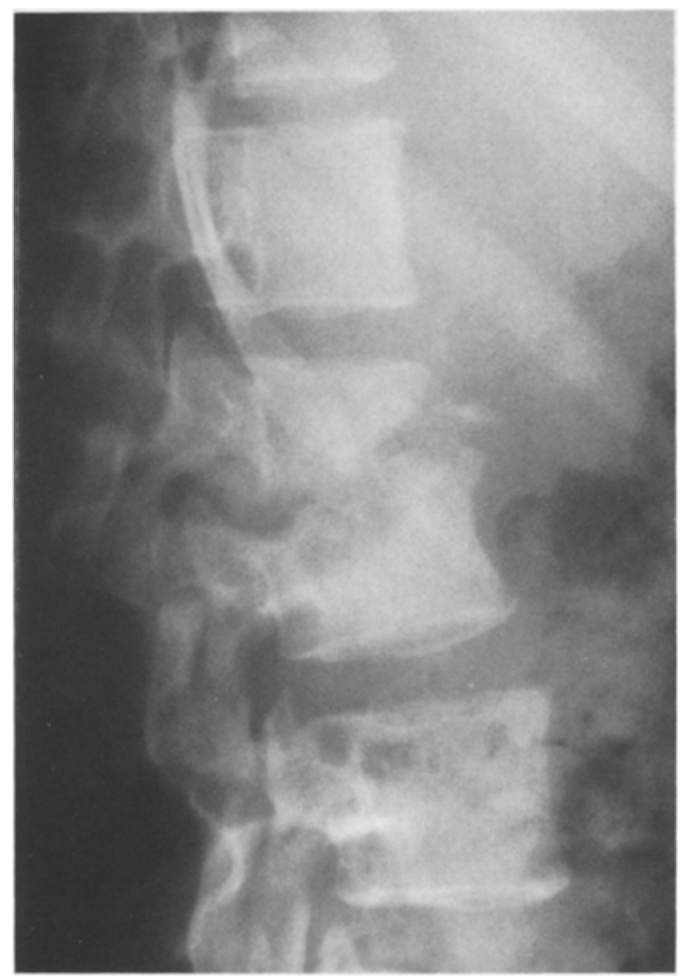

Fig. 1. Typical destructive lesion due to bacteria in a lumbar vertebral body and disk. 

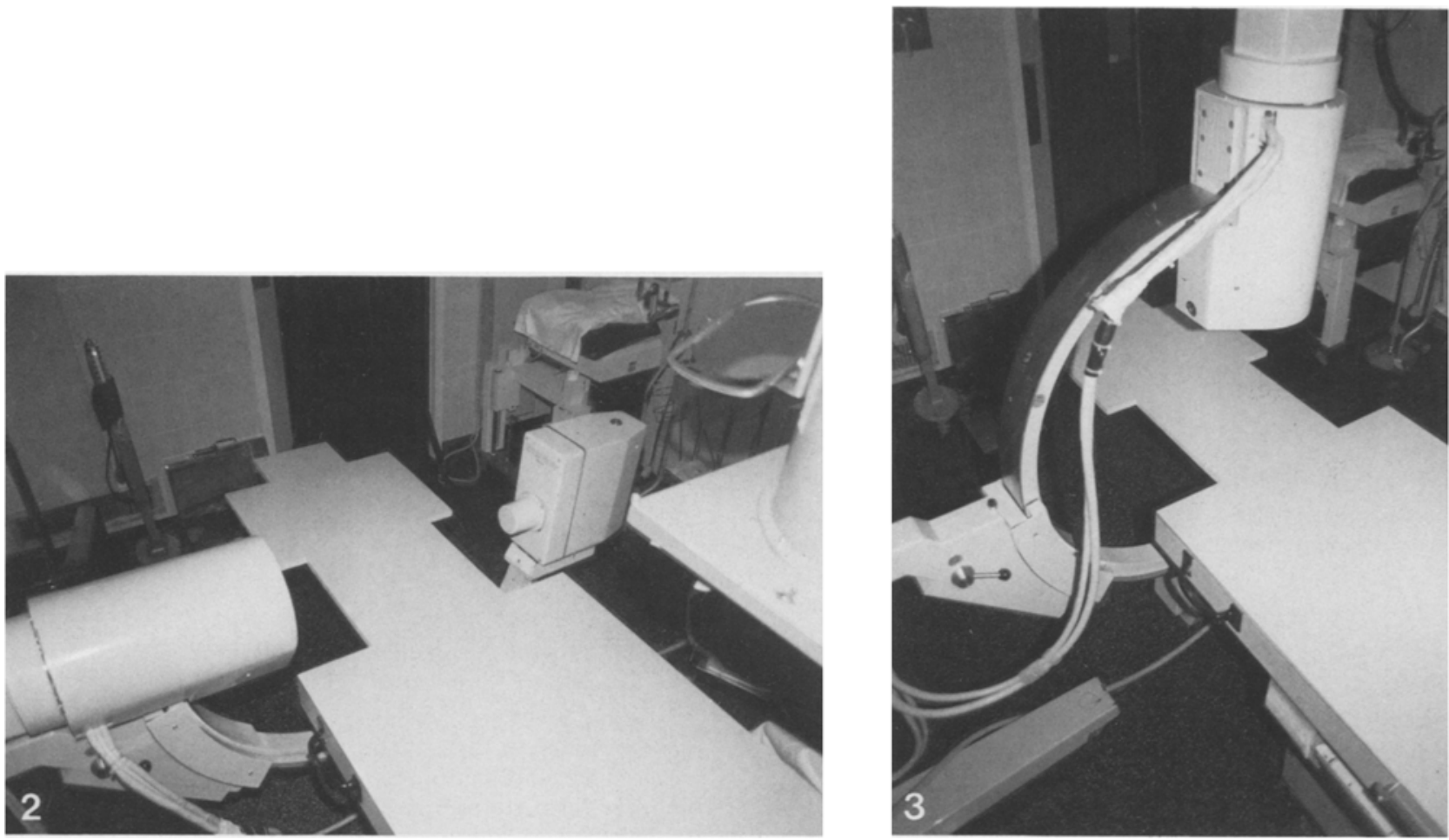

Figs. 2, 3. A cut-out in the moving top table greatly facilitates vertical to horizontal beam fluoroscopy

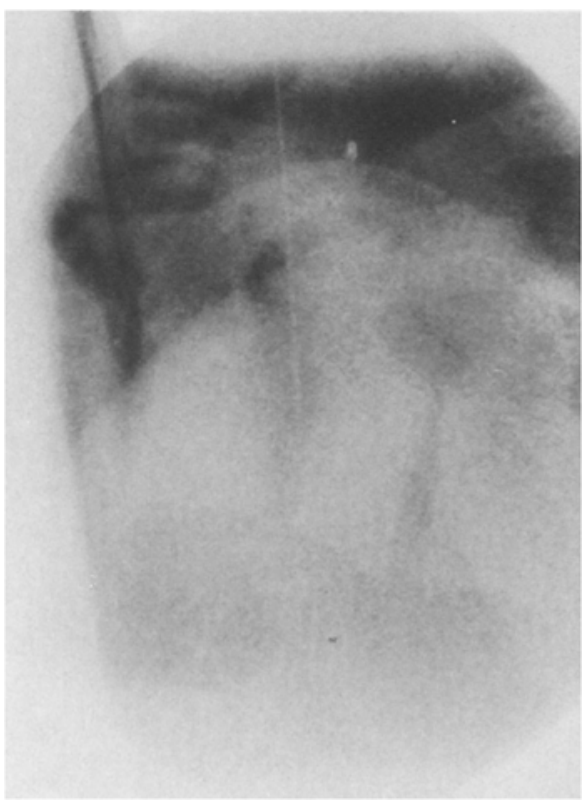

Fig. 4. Video disk verification of final needle position

designed cut-out board is very helpful. Getting a proper "setup" of patient, table, and fluoroscope will save time for both the patient and physician.

A skin anesthetic wheal is raised 6 to $8 \mathrm{~cm}$ lateral to the midline. The cutaneous tissue is cut with a blade. The 22 gauge needle is directed into the destroyed bone and dise with the final needle position copied on the video recorder (Fig. 4). Suc- tion is applied. In only one of our cases was pus obtained in which case the procedure is completed. After nonproductive aspiration $0.5 \mathrm{cc}$ of nonbacteriostatic saline (REPEAT use only pure saline!) is injected and aspiration again attempted. The aspiration attempt is usually "dry" but nevertheless contains the bacteria. The entire needle-syringe complex is carried to the bacteriology department for culture and sensitivity.

\section{Results}

Fourteen of our 15 patients were intravenous drug users. Fourteen cases had a pseudomonas infection - the other was staphylococcal. In one patient the initial attempt was sterile but another aspirate one week later was positive. The rest were positive on first attempt. There were no complications.

\section{Discussion}

Percutaneous needle aspiration is safe, cost effective, and available to an out-patient. No complications occurred in our patients. In theory any needle procedure in this region could cause: (a) injury to vascular structures such as the inferior vena cava, lumbar veins, or aorta, (b) spread of infection along the needle tract, or (c) injury to the kidneys.

Ottolenghi et al. published their observations and technique of large needle vertebral biopsy in 
1948 and in 1969 [4]. Armstrong in 1977 [1] recommended early aspiration of infection enabling prompt treatment. We do not use, or need, general anesthesia as they have recommended. We specifically do not inject deep anaesthesia as this could sterilize the area near the needle point and give a false negative sterile result. McLoughlin in 1978 [3] reviewed fine needle techniques in general but did not discuss diagnosis of infection.

\section{References}

1. Armstrong P, Chalmers AH, Green G, Irving JD (1978) Needle aspiration biopsy of the spine in suspected disc space infection. Br J Radiol 51:333

2. Martin HE, Ellis EB (1934) Aspiration biopsy. Surg Gynecol Obstet $59: 578$

3. McLoughlin MJ, Ho CS, Tao LC (1978) Percutaneous needle aspiration biopsy. Can Med Assoc J 119:1324

4. Ottolenghi CE (1969) Aspiration biopsy of the spine. J Bone Joint Surg $[\mathrm{Am}] 51: 1531$ 